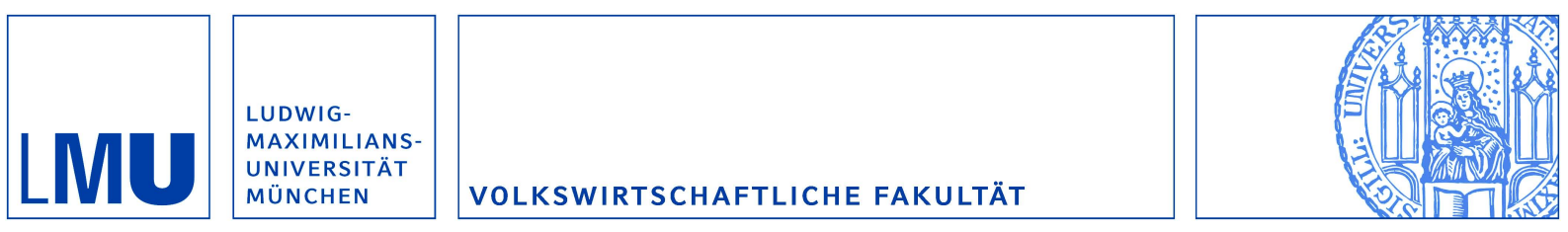

Eichhorn, Christoph und Sahm, Marco:

Why were FIFA World Cup Tickets so cheap?

Munich Discussion Paper No. 2007-2

Department of Economics

University of Munich

Volkswirtschaftliche Fakultät

Ludwig-Maximilians-Universität München

Online at https://doi.org/10.5282/ubm/epub. 1357 


\title{
Why were FIFA World Cup Tickets so cheap? Monopoly Pricing, Demand Quality and Two-Sided Markets
}

\author{
Christoph Eichhorn Marco Sahm* \\ University of Munich
}

January 2007

\begin{abstract}
We examine the pricing decision of a multi-product monopolist in a two-sided market where the type structure of buyers on one side of the market is an important determinant of profit on the other side. In this situation it might be optimal to set prices below the maximum sellout price and to ration demand by a random mechanism in the first market to reach a type distribution more favorable for sales in the other market. The model establishes demand quality as an alternative link between markets in addition to standard quantitative effects and explains frequently observed underpricing, e.g. in the (sports) entertainment industry. It also provides an explanation for the effort a monopolist incurs to deter from resale.
\end{abstract}

Keywords: Underpricing, Demand Rationing, Resale Deterrence

JEL classification: L12, D42, D45

${ }^{*}$ Department of Economics, Ludwig-Maximilians-Universität München, Ludwigstraße 28, 80539 Munich, Germany, Tel.: +49-89-2180-1392, Fax: +49-89-2180-3128, E-mail: Marco.Sahm@lrz.uni-muenchen.de. We would like to thank Markus Reisinger as well as participants of the Annual Meeting of the Scottish Economic Society 2006 in Perth, the Spring Meeting of Young Economists 2006 in Seville and the Public Finance Workshop as well as the Theory Workshop at LMU Munich for helpful comments. 


\section{Introduction}

The FIFA soccer world championships are one of the most important events in sports - and the entertainment industry. The sale of tickets for its 2006 edition in Germany has been a great deal of public discussion. During the first selling-period in February and March 2005, ticket prices ranged from 35 Euro for a group match in the forth seating category to 600 Euro for the final in the first category. Though some reader may think that was not cheap, demand exceeded supply already three days after ticket orders were possible. At the end of the selling-period excess demand amounted to more than factor 10. The FIFA rationed the demand by a random allocation of tickets. Moreover, the tickets were personalized in order to prevent resale in the black market. Resale of tickets was allowed only at the purchase price via an official platform installed and controlled by the FIFA. Given the huge excess demand it is, prima facie, surprising that ticket prices were not set higher ex ante or determined by an auction-like mechanism. Why were the tickets so cheap? And why did the FIFA incur so much effort to deter customers from resale?

The model developed in this paper simultaneously solves both the underpricing puzzle and the one of resale deterrence without giving up the assumption of profit maximizing behavior. We examine the pricing decision of a multi-product monopolist in a two-sided market where the type structure of buyers on one side of the market is an important determinant of profit on the other side. In this situation it might be optimal to lower prices below the maximum sellout price and to ration demand by a random mechanism in the first market to reach a type distribution more favorable for sales in the other market. Moreover, in order to maintain the intended type structure in the first market, the monopolist might spend effort taking action against resale.

\section{Multi-product monopoly pricing and two-sided markets}

A fundamental result of the literature on optimal pricing of a multi-product monopolist is that optimal price structures reflect interdependent demands (Tirole, 1988). To maximize profits a multi-product monopolist sets prices such that the sum of marginal revenues across all markets is equal to the marginal costs for each good. If the goods are substitutes the monopolist will optimally charge a higher price than if the goods are produced by separate monopolists, and vice versa for goods that are complements.

Similarly, the literature on two-sided markets investigates optimal pricing if demand externalities are present (Rochet and Tirole, 2003). The seller acts as an intermediary who brings two groups together by doing business with 
both of them. To maximize his own profit the seller charges a lower price on one side of the market if a negative externality from the other side exists, and a higher price if the externality is positive.

In both cases, the link between the product markets is brought about by quantity effects. Therefore price structures that do not imply a change in the transaction volume in the market, from which a one-sided link to another market originates, are equivalent. In particular, prices below the maximum price for which the product is sold at the production capacity in the first market, call it maximum sellout price, seem to be inefficient and unreasonable. However, like in the FIFA World Cup example above, such prices are frequently observed, especially in the entertainment industry. Tickets for sports and music events are often sold out early before the event and would probably be sold out even at significantly higher prices.

We argue that this phenomenon does not originate from a quantitative but a qualitative externality that is still present if the monopolist sells at capacity: The demand quality, i.e. the type structure of buyers with respect to an unobserved individual characteristic, in one market (market 1) may be an important determinant of profit in another otherwise unrelated market (market 2). Put differently, the (expected) distribution of the unobserved individual characteristic among customers in market 1 exerts a (positive) externality on the demand of customers in market 2. Of course, a rational monopolist takes this effect into account. Given that demand quality reacts to consumer prices in market 1 , he can use the price structure as a screening device: If no superior discrimination procedures can be used, he might find it optimal to set a price below the maximum sellout price and ration demand by a random mechanism in order to reach a type distribution among customers in market 1 more favorable for sales in market 2 . Moreover, he might incur effort to credibly deter customers from resale in order to maintain the intended type structure in market 1 .

Coming back to the introductory example, in light of this general argument the selling strategy for the FIFA World Cup tickets can be easily rationalized. Successful marketing of sports events - especially sports events that are widely broadcasted in the media - viably depends on the atmosphere in the stadium which is influenced by the types of individuals among the audience, e.g. their willingness to cheer. If this willingness to cheer is negatively related to income and tickets are a normal commodity, higher admission charges lower the (expected) willingness to cheer among spectators. Put differently, setting high ticket prices drives out high-quality fans, beclouds the atmosphere, and hence leads to a loss of revenue in markets that suffer from low emotions, e.g. the one for sponsorship contracts or merchandizing products. Moreover, the type structure among spectators intended by low ticket 
prices can only be maintained if the resale of tickets in the black market is credibly prevented.

\section{Related Literature}

Our paper contributes to two strands of the literature. First, it establishes demand quality as an alternative link between markets in addition to standard quantitative effects in the literature on monopolistic price setting in two-sided markets. Second, it adds a new explanation to the literature dealing with the phenomenon of underpricing, particularly in the (sports) entertainment industry.

The similarity between our model and the existing literature on two-sided markets - an overview is provided by Rochet and Tirole (2004) - arises from the fact that the customer base in market 1 determines sales in market 2 . However, only the quality of the customer base matters in our case. A related idea can be found in the literature on efficient matching (Damiano and Li, 2004).

There are alternative explanations for the underpricing phenomenon that may occur independently of the one proposed in our paper.

Several studies emphasize the role of fairness (Kahnemann et al., 1992), loyalty (Salant, 1986) or distributional aspects but lead away from the standard assumption of a profit maximizing organizer. However, it has been shown that, for example, ticket prices in the American baseball league are determined by a monopolistic profit maximizing strategy (Alexander, 2001).

Swafford (1999) shows that low prices might be optimal in a situation with demand uncertainty. Although uncertainty might always play a role in real world markets, it is beyond doubt that many entertainment events where underpricing is observed are expected to sell out at these prices.

The reason, first suggested by Becker (1991), that allowing additional fans to enter at lower prices increases everyone's willingness to pay for participating in the event, leads into the same direction as our paper. However, in case of a sellout, no additional spectators are possible. We argue instead that the seller aims at the right ones.

The remainder of this paper is organized as follows: The formal modal is set up in Section 2 and used to derive the main results in Section 3. Section 4 illustrates the mechanism and the results by means of a simple example. Finally, possible extensions and scope for further research are discussed in section 5 . 


\section{The model}

We consider a partial equilibrium model of a two-product monopoly. The monopolist sells one commodity, called tickets $t$, to individuals in the $\mathrm{t}$ market and another commodity, called sponsorship contracts $x$, to firms in the x-market.

\section{Individuals' demand and demand quality}

Assume that there is a set of individuals $I$; for analytical convenience suppose $I:=[0,1] .^{1}$ Individuals $i \in I$ differ with respect to their exogenous endowment with income $y^{i}$, which is distributed on $[\underline{y}, \bar{y}] \subset \mathbb{R}_{0}^{+}$with the cumulative distribution function (cdf) $F$ and density $\bar{f}$, and another unobservable characteristic $e^{i}$, which is distributed on $[\underline{e}, \bar{e}] \subset \mathbb{R}^{+}$with the cdf $\mathrm{G}$ and density g. For the sake of concreteness, we refer to this characteristic $e^{i}$ as individual willingness to show emotions or, for short, emotionality. Note, however, that this is just one of arbitrarily many real world interpretations.

Each individual $i \in I$ exhibits preferences over the consumption of two goods, tickets $t$ and other commodities $q$, according to the strictly quasi concave utility function

$$
\begin{aligned}
u: \mathbb{R}^{2} & \rightarrow \mathbb{R}, \\
\left(t^{i}, q^{i}\right) & \mapsto u\left(t^{i}, q^{i}\right) .
\end{aligned}
$$

The price for tickets is referred to as $p_{t}$, the price for other commodities is normalized to 1. Each consumer takes the prices of the goods as given and maximizes utility by choosing its preferred bundle of goods in his respective budget set. In particular we assume that either one ticket is demanded if the individual's valuation is high enough or none at all:

$$
t^{i}\left(p_{t}\right)=\left\{\begin{array}{l}
0, \text { if } v^{i}<p_{t}, \\
1, \text { if } p_{t} \leqslant v^{i}
\end{array}\right.
$$

Thereby, $v^{i} \in[\underline{v}, \bar{v}] \subset \mathbb{R}_{0}^{+}$denotes individual $i$ 's willingness to pay for the ticket and is defined by ${ }^{2}$

$$
u\left(1, y^{i}-v^{i}\right)=u\left(0, y^{i}\right)
$$

We will assume in the following that the willingness to pay rises with income (but is independent from emotionality).

\footnotetext{
${ }^{1} \mathrm{~A}$ case of finitely many individuals is discussed in the example below.

${ }^{2}$ Note that $v^{i}$ cannot be defined like this for arbitrary utility functions; in particular, we exclude utility functions with the property $\lim _{t \rightarrow 0} \frac{\partial}{\partial t} u(t, q)=+\infty$, for $q>0$.
} 
Assumption 1 For all $i \in I$, assume $\frac{\mathrm{d} v^{i}}{\mathrm{~d} y^{i}}>0$.

Equation (2) implicitly defines an invertible function

$$
y:[\underline{v}, \bar{v}] \rightarrow[\underline{y}, \bar{y}], v^{i} \mapsto y\left(v^{i}\right)=y^{i} ;
$$

applying the implicit function theorem yields

$$
\frac{\mathrm{d} v^{i}}{\mathrm{~d} y^{i}}=\frac{\frac{\partial}{\partial q} u\left(1, y^{i}-v^{i}\right)-\frac{\partial}{\partial q} u\left(0, y^{i}\right)}{\frac{\partial}{\partial q} u\left(1, y^{i}-v^{i}\right)} .
$$

Hence, Assumption 1 is equivalent to suppose that $\frac{\partial}{\partial q} u\left(1, y^{i}-v^{i}\right)>\frac{\partial}{\partial q} u\left(0, y^{i}\right)$. This condition is satisfied in particular for separable utility functions $u(t, q)=$ $\hat{u}(t)+\tilde{u}(q)$, where $\tilde{u}$ is strictly concave.

As an immediate consequence of Assumption 1, total demand for tickets

$$
t\left(p_{t}\right)=\int_{y\left(p_{t}\right)}^{\bar{y}} 1 \cdot f(y) d y=1-F\left(y\left(p_{t}\right)\right)
$$

decreases as the price $p_{t}$ increases, since $\frac{\mathrm{d} t\left(p_{t}\right)}{\mathrm{d} p_{t}}=-f\left(y\left(p_{t}\right)\right) \frac{\mathrm{d} y\left(p_{t}\right)}{\mathrm{d} p_{t}}$.

Lemma 1 Under Assumption 1, $\frac{\mathrm{d} t\left(p_{t}\right)}{\mathrm{d} p_{t}}<0$.

In the remainder of this subsection we characterize what we will call demand quality, namely the type structure of individuals who demand tickets given a price $p_{t}$ with respect to their willingness to show emotions. To this end we make an assumption which is somewhat more specific and debatable. We assume the average emotionality $\tilde{e}(y):=E_{g}\left(e^{i} \mid y^{i} \geq y\right)$ of individuals with a minimum income of $y$ to decrease as $y$ increases.

Assumption 2 For all $y \in[\underline{y}, \bar{y}]$, assume $\frac{\mathrm{d} \tilde{e}(y)}{\mathrm{d} y}<0$.

This may just be seen as an empirically testable sociological hypothesis, for which there is a lot of anecdotal evidence. It is, however, beyond the scope of our analysis to answer this empirical question. Our main concern is to establish demand quality as a possible channel at which monopolistic price setting behavior is influenced. ${ }^{3}$

Given Assumption 2, the average emotionality $\tilde{e}\left(y\left(p_{t}\right)\right)$ of customers demanding tickets in the t-market obviously decreases as the ticket price $p_{t}$ increases, since $\frac{\mathrm{d} \tilde{e}\left(y\left(p_{t}\right)\right)}{\mathrm{d} p_{t}}=\frac{\mathrm{d} \tilde{e}(y)}{\mathrm{d} y} \frac{\mathrm{d} y\left(p_{t}\right)}{\mathrm{d} p_{t}}$.

\footnotetext{
${ }^{3}$ Alternatively, the more suspicious reader may interpret the characteristic $e^{i}$ as individual $i$ 's age and more comfortably assume a positive correlation between age and income. Then of course, since age is observable, in what follows one has to make the unpleasant (but not unrealistic) additional assumption that the monopolist is not allowed to discriminate directly by age.
} 
Lemma 2 Under Assumptions 1 and $2, \frac{\mathrm{d} \tilde{e}\left(y\left(p_{t}\right)\right)}{\mathrm{d} p_{t}}<0$.

To summarize the results so far, an increase in the ticket price $p_{t}$ does not only decrease the quantity $t$ of demand in the t-market but also its quality, namely the average emotionality $\tilde{e}$.

\section{Firms' demand}

We assume that the firms' demand for sponsorship contracts $x$ with the monopolist in the x-market does not only depend on the price $p_{x}$ for such contracts but also on the expected emotionality $\tilde{e}$ in the t-market. The latter may be the case because high emotions during the event might enhance the effect of advertisement for contracting firms and therefore boost the demand for their products increasing their profits. More specifically, we make the following

Assumption 3 For all $p_{x} \geq 0$ and $\tilde{e} \in[\underline{e}, \bar{e}]$, assume $\frac{\partial x\left(p_{x}, \tilde{e}\right)}{\partial p_{x}}<0$ and $\frac{\partial x\left(p_{x}, \tilde{e}\right)}{\partial \tilde{e}}>0$.

\section{Monopolistic profit maximization}

The multi-product monopolist simultaneously maximizes his profit $\pi$ from sales in the t-market and the x-market by setting the respective prices $p_{t}$ and $p_{x}$ observing the respective demands $t\left(p_{t}\right)$ and $x\left(p_{x}, \tilde{e}\left(y\left(p_{t}\right)\right)\right)$. However, supplying tickets the monopolist faces a technological constraint $t \leq \bar{t}$, which may be interpreted as the maximum venue capacity, e.g. the number of seats within a stadium. The maximum ticket price that leads to demand at capacity $\bar{t}$,

$$
\hat{p}_{t}:=\max \left\{p_{t} \mid t\left(p_{t}\right) \geqslant \bar{t}\right\},
$$

will be referred to as the maximum sellout price. Note that by Lemma 1, $\hat{p}_{t}$ is the unique price fulfilling $t\left(\hat{p}_{t}\right)=\bar{t}$. Whenever ticket demand $t\left(p_{t}\right)$ exceeds the capacity $\bar{t}$, i.e. whenever $p_{t}<\hat{p}_{t}$, the monopolist uses a fair random procedure to ration demand. ${ }^{4}$

For analytical convenience, assume that the monopolist's production costs can be described by an additively separable function $C(t, x)=C_{t}(t)+C_{x}(x)$. Hence, the profit function takes the following form:

$$
\pi\left(p_{t}, p_{x}\right)= \begin{cases}p_{t} \bar{t}+p_{x} x\left(p_{x}, \tilde{e}\right)-C_{t}(\bar{t})-C_{x}\left(x\left(p_{x}, \tilde{e}\right)\right), & p_{t} \leq \hat{p}_{t} \\ p_{t} t\left(p_{t}\right)+p_{x} x\left(p_{x}, \tilde{e}\right)-C_{t}\left(t\left(p_{t}\right)\right)-C_{x}\left(x\left(p_{x}, \tilde{e}\right)\right), & p_{t}>\hat{p}_{t}\end{cases}
$$

\footnotetext{
${ }^{4}$ The random procedure is fair in the sense that any individual demanding a ticket is chosen with the same probability. The existence of superior discrimination mechanisms is discussed in Section 5.
} 


\section{The Results}

We now formally describe a scenario for the following observation: If demand quality in the t-market is an important determinant for demand in the $\mathrm{x}$ market, it may well be optimal to set $p_{t}$ below the maximum sellout price.

To see this, consider a situation in which the monopolist optimally chooses the price $\hat{p}_{x}$ in the x-market given that he charges the maximum sellout price $\hat{p}_{t}$ and sells tickets at capacity $\bar{t}$. In such a case, the partial derivatives of the profit function are given by

$$
\begin{aligned}
\frac{\partial \hat{\pi}}{\partial p_{t}} & =\bar{t}+\left(\hat{p}_{x}-\frac{\mathrm{d} \hat{C}_{x}}{\mathrm{~d} x}\right) \frac{\partial \hat{x}}{\partial \tilde{e}} \frac{\mathrm{d} \hat{e}}{\mathrm{~d} p_{t}} \\
\frac{\partial \hat{\pi}}{\partial p_{x}} & =\hat{x}+\left(\hat{p}_{x}-\frac{\mathrm{d} \hat{C}_{x}}{\mathrm{~d} x}\right) \frac{\partial \hat{x}}{\partial p_{x}}
\end{aligned}
$$

where $\hat{\pi}:=\pi\left(\hat{p}_{t}, \hat{p}_{x}\right), \hat{x}:=x\left(\hat{p}_{x}, \hat{e}\right), \hat{e}:=\tilde{e}\left(y\left(\hat{p}_{t}\right)\right)$, and $\hat{C}_{x}:=C_{x}(\hat{x})$.

Using equation (6) and Assumption 3, optimality of $\hat{p}_{x}$ implies that $\hat{p}_{x}-\frac{\mathrm{d} \hat{C}_{x}}{\mathrm{~d} x}=-\frac{\hat{x}}{\partial \hat{x} / \partial p_{x}}>0$. Hence, by Lemma 2 and Assumption 3, the second term in the sum on the right hand side of equation (5) is negative. If this negative effect is strong enough, $\frac{\partial \hat{\pi}}{\partial p_{t}}<0$, i.e. marginal profit is negative, indicating additional profits if the price $p_{t}$ is reduced below its maximum sellout level $\hat{p}_{t}$. Those considerations prove

Proposition 1 Under Assumptions 1 - 3, the optimal price $p_{t}^{*}$ in the $t$ market lies below the maximum sellout price $\hat{p}_{t}$, if and only if the average quality $\tilde{e}$ of customers in the t-market is sufficiently important for the demand in the $x$-market; more formally:

$$
p_{t}^{*}<\hat{p}_{t} \quad \Leftrightarrow \quad \bar{t}<-\left(\hat{p}_{x}-\frac{\mathrm{d} \hat{C}_{x}}{\mathrm{~d} x}\right) \frac{\partial \hat{x}}{\partial \tilde{e}} \frac{\mathrm{d} \hat{e}}{\mathrm{~d} p_{t}} .
$$

Proposition 1 asserts, that it is optimal to set $p_{t}$ below the maximum sellout price, whenever the marginal decrease in profit in the t-market from the lower price is lower than the marginal increase in profit in the $\mathrm{x}$-market from the augmentation in demand quality in the t-market. The following Corollary clarifies how prices are actually chosen in this case.

Corollary 1 If $p_{t}^{*}<\hat{p}_{t}$, the optimal monopolistic price levels $p_{t}^{*}, p_{x}^{*}$ are given 
by the following conditions:

$$
\begin{aligned}
p_{t}^{*}=0 \quad \text { or } \quad \frac{\partial \pi^{*}}{\partial p_{t}} & =\bar{t}+\left(p_{x}^{*}-\frac{\mathrm{d} C_{x}^{*}}{\mathrm{~d} x}\right) \frac{\partial x^{*}}{\partial \tilde{e}} \frac{\mathrm{d} \tilde{e}^{*}}{\mathrm{~d} p_{t}}=0, \\
\frac{\partial \pi^{*}}{\partial p_{x}} & =x^{*}+\left(p_{x}^{*}-\frac{\mathrm{d} C_{x}^{*}}{\mathrm{~d} x}\right) \frac{\partial x^{*}}{\partial p_{x}}=0
\end{aligned}
$$

where $\pi^{*}:=\pi\left(p_{t}^{*}, p_{x}^{*}\right), x^{*}:=x\left(p_{x}^{*}, \tilde{e}^{*}\right), \tilde{e}^{*}:=\tilde{e}\left(y\left(p_{t}^{*}\right)\right)$, and $C_{x}^{*}:=C_{x}\left(x^{*}\right)$.

So far, the analysis has been conducted as if the resale of tickets were impossible or, at least, unlikely to occur. Note that in a situation where ticket demand is randomly rationed, resale deteriorates the customer quality since only individuals with high valuations (and low quality) want to buy the good in the black market. Consequently, the expected emotionality and thereby the demand for sponsorship contracts decrease. Hence, the monopolist has an incentive to credibly and effectively deter customers from resale because otherwise his profits diminish. Ex ante, i.e. at the time the monopolist decides about the prices and before trade has taken place, the difference between the optimal profit $\pi^{*}$ and the profit $\hat{\pi}$ charging the maximum sellout price serves as an upper bound for the amount the monopolist is willing to spend for appropriate measures of deterrence.

Corollary 2 Suppose that Assumptions 1 - 3 hold and resale of tickets is likely to occur. Then the optimal price $p_{t}^{*}$ in the $t$-market lies below the maximum sellout price $\hat{p}_{t}$, if and only if the average quality $\tilde{e}$ of customers in the t-market is sufficiently important for the demand in the $x$-market, i.e. $\bar{t}<-\left(\hat{p}_{x}-\frac{\mathrm{d} \hat{C}_{x}}{\mathrm{~d} x}\right) \frac{\partial \hat{x}}{\partial \tilde{e}} \frac{\mathrm{d} \hat{e}}{\mathrm{~d} p_{t}}$, and the profit differential $\pi^{*}-\hat{\pi}$ suffices to finance credible and effective resale deterrence.

\section{A simple example}

To illustrate the main idea of our model, consider the following example. There are only two individuals within the economy: Lady Rich has a high income $\bar{y}$ and hence a high willingness to pay for a ticket $\bar{v}$ but a low willingness to show emotions $\underline{e}$. Mr. Happy, on the other hand, has a low income $y$ and hence a low willingness to pay for a ticket $\underline{v}$ but a high willingness to show emotions $\bar{e}$.

The monopolist has zero production costs but is constrained by a stadium capacity of one single seat $(\bar{t}=1)$. Hence, the maximum sell-out price on the t-market is given by Lady Riche's willingness to pay: $\hat{p}_{t}=\bar{v}$. If the monopolist charges this price, demand quality equals Lady Riche's low willingness to 


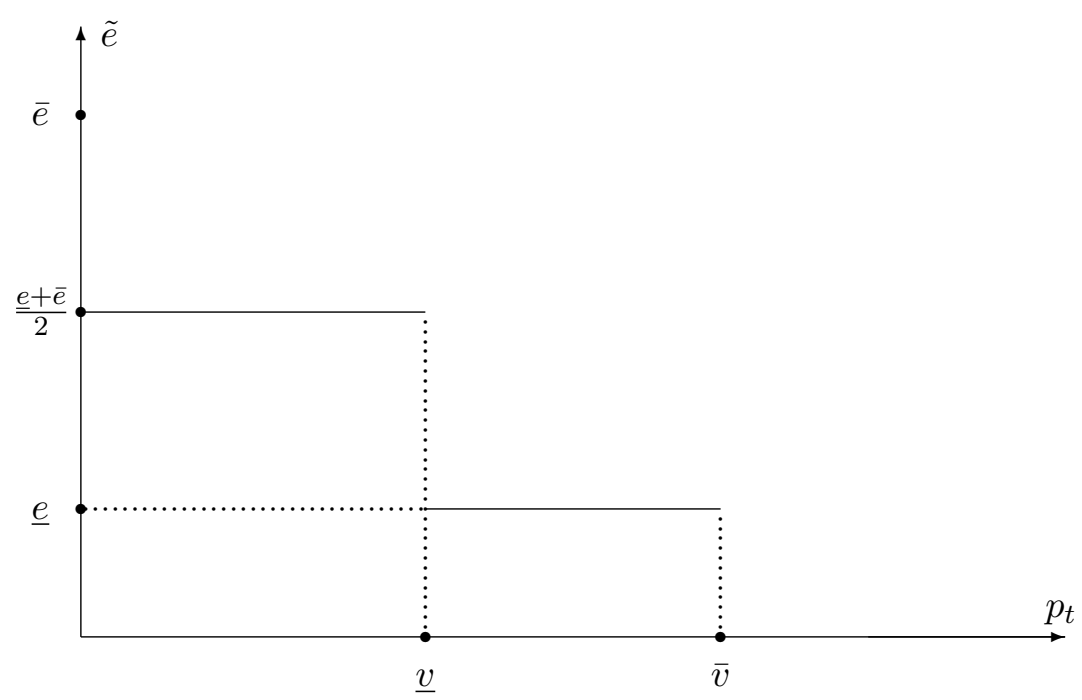

Figure 1: Average consumer quality.

show emotions: $\tilde{e}(\bar{v})=\underline{e}$. If, however, he alternatively charges a ticket price amounting to Mr. Happy's willingness to pay, $p_{t}^{*}=\underline{v}$, and randomly rations demand, expected demand quality equals the equally weighted sum of both emotionalities $\tilde{e}(\underline{v})=\frac{\underline{e}+\bar{e}}{2}$. Figure 1 illustrates the relation between the price and the (average) quality of the customers.

Then, though the monopolist looses revenue in the first market, this loss might be well offset by higher revenues in a second market $\mathrm{x}$, if quality is an important determinant of demand in that x-market. Consequently, he chooses the price $p_{t}^{*}=\underline{v}$ below the maximum sellout price $\hat{p}_{t}=\bar{v}$ if and only if

$$
\bar{v}+\bar{p}_{x} \cdot x\left(\bar{p}_{x}, \underline{e}\right)<\underline{v}+\underline{p}_{x} \cdot x\left(\underline{p}_{x}, \frac{\underline{e}+\bar{e}}{2}\right),
$$

where $\bar{p}_{x}$ is the optimal price given $p_{t}=\bar{v}$ and $\underline{p}_{x}$ is the optimal price given $p_{t}=\underline{v}$. Moreover, the difference between both sides of inequality (9) serves (ex-ante) as an upper bound for the effort the monopolist is willing to spend in order to deter Mr. Happy from resale.

\section{Concluding remarks}

We have shown that the price structure a multi-product monopolist chooses is not only affected by quantity effects across markets but also by quality effects. In our framework, a higher quality of the customer base in one market exerts a positive production externality and leads to higher sales 
in an otherwise unrelated market. We have applied the model to explain underpricing of admission tickets in the entertainment industry. Moreover, the model is able to elucidate the effort a monopolist might undertake in order to deter customers in the first market from resale.

While underpricing and rationing of tickets is frequently observed within the entertainment industry ${ }^{5}$ resale deterrence by the organizer itself - like in the case of the FIFA World Cup - is a new phenomenon. ${ }^{6}$ This may reflect the fact that legal provisions or transaction costs that in former hampered resale anyway, recently can be easily circumvented by the anonymity and accessability of the internet. Unlike before, nowadays it is the underpricing monopolist himself who has to take action against resale in order to assure the intended demand quality.

The character of our analysis is positive; in particular it takes as given that the monopolist uses a random procedure to ration demand. From a theoretic point of view there certainly are superior screening mechanisms in order to discriminate agents with respect to the unobservable characteristic. In the example discussed, one could think of (personalized) queuing, i.e. making use of different opportunity costs, or (beauty) contests. However, under the assumptions made in the model, underpricing of tickets is necessary to increase demand quality in that market even if, afterwards, the resulting excess demand is rationed more effectively than by random choice. Consequently, our qualitative results do not hinge on the assumption of random rationing.

From the viewpoint of Public Economics it is interesting to consider the welfare implications of the pricing strategy discussed above. Note that we focus on the case where the monopolist sells at capacity in the t-market. Consequently, unlike in the $\mathrm{x}$-market, in the t-market there is no inefficiency arising out of a quantity that is too low. Nevertheless, an inefficiency arises in the t-market if the monopolist sells to individuals with valuations lower than the maximum sellout price. ${ }^{7}$ Hence, from a (utilitarian) welfare per-

\footnotetext{
${ }^{5}$ Indeed, even in the case of binding capacity constraints, ticket prices of 0 often can be found if media platforms (like newspapers, radio- or TV-stations) organize a music or sports event which is sponsored by firms using the event for promotional activities.

${ }^{6}$ On 06/03/2006 Kalamazoo, a British security print enterprize, reports in the rubric Latest News on its web-page that it 'currently prints personalised season tickets for a number of premiership football clubs, which when checked against official forms of ID such as passports and driving licences successfully controls touting' (http://www.kalamazoosecure.co.uk/index.asp?locID=38\&docID=156). On 10/11/2006 KölnTicket, a German ticket agency, reports in the rubric $A k$ tuelles on its web-page the introduction of personalized tickets for concerts as well (http://www.koelnticket.de/index.php?ref_mandantid=1\&mapid=aktuelles).

${ }^{7}$ This is the reason why a black market emerges and resources are spent to foreclose it. Note that the underpricing strategy will never lead to a Pareto improvement, since it
} 
spective, the relevant question is whether this inefficiency in the t-market is offset by the efficiency gain in the $\mathrm{x}$-market, which is due to the positive externality of higher emotions in the case of underpricing. Unfortunately, even in our simple partial equilibrium framework, this question cannot be answered unambiguously without further assumptions. ${ }^{8}$ To see why, consider the case where the monopolist optimally sets a ticket price below the maximum sellout price. He does so if $\pi^{*}>\hat{\pi}$, i.e. if the revenue loss from underpricing in the t-market is overcompensated by the additional profit in the $\mathrm{x}$-market. However, he does neither take into account the resulting decrease in consumer surplus in the t-market nor the increase of firms' profits in the $\mathrm{x}$-market. If the former is big while the latter is small, total benefit might shrink despite the monopolist's increasing gain.

\section{References}

Alexander, D. L. (2001). Major league baseball: Monopoly pricing and profit maximizing behaviour. Journal of Sports Economics, 2(4):341-355.

Anderson, S. P. and Coate, S. (2005). Market provision of broadcasting: A welfare analysis. Review of Economic Studies, 72:947-972.

Becker, G. (1991). A note on restaurant pricing and other examples of social influences on price. Journal of Political Economy, 99(5):1109-1116.

Damiano, E. and Li, H. (2004). Price discrimination and efficient matching. Unpublished Working Paper.

Kahnemann, D., Knetsch, J., and Thaler, R. (1992). Fairness as a constraint on profit seeking: Entitlements in the market. American Economic Review, 76(4):728-741.

Rochet, J.-C. and Tirole, J. (2003). Platform competition in two-sided markets. Journal of European Economic Association, 1(4):990-1029.

Rochet, J.-C. and Tirole, J. (2004). Two-sided markets: an overview. Mimeo.

Salant, D. (1986). Price setting in professional teams sports. In Sommers, P., editor, Diamonds are Forever: The Business of Baseball, pages 77-90. Brookings Institutions, Washington.

almost surely leaves some individuals worse off.

${ }^{8}$ This ambiguity resembles the results of several studies that examine the welfare effects of pricing decisions in two-sided markets, see e.g. Anderson and Coate (2005) and the references within. 
Swafford, J. (1999). Arbitrage, speculation and public policy toward ticket scalping. Public Finance Review, 27:531-540.

Tirole, J. (1988). The Theory of Industrial Organization. MIT Press, Camebridge, London. 